\title{
INTEGRASI INFORMASI KESEHATAN PADA INSTANSI KESEHATAN DI KOTA PEKALONGAN MELALUI SISTEM INFORMASI LAYANAN KESEHATAN
}

\author{
Eko Budi Susanto, M. Faizal Kurniawan, P.A. Christianto \\ Program Studi Teknik Informatika \\ STMIK Widya Pratama Pekalongan \\ Korespondensi:eqo_bs@yahoo.com
}

\begin{abstract}
Availability of health care information system is one factor that can not be separated from health system in a country. With the system, the community will be facilitated to get health services from various health institutions that exist. In addition, the community can play an active role in providing various information about health that occurred in the environment. At present, the community's need for integrated health care information is very important, so that people can make decisions quickly and accurately. In the previous research has produced prototype health care information system. The prototype is made only on the side of the general user / community that will access the healthcare information system. In this research will be built data integration on health care information system administrator page that can integrate data at health agency.
\end{abstract}

Keywords: Information center, service health

\begin{abstract}
ABSTRAK
Ketersediaan sistem informasi layanan kesehatan merupakan salah satu faktor yang tidak dapat dipisahkan dari sistem kesehatan di suatu negara. Dengan sistem tersebut, masyarakat akan dimudahkan untuk mendapatkan layanan kesehatan dari berbagai institusi kesehatan yang ada. Selain itu, masyarakat dapat berperan aktif dalam memberikan berbagai informasi tentang kesehatan yang terjadi di lingkungannya. Saat ini, kebutuhan masyarakat akan informasi layanan kesehatan yang terintegrasi, sangatlah penting, sehingga masyarakat dapat mengambil keputusan dengan cepat dan tepat. Pada penelitian sebelumya telah dihasilkan prototipe sistem informasi layanan kesehatan. Prototipe tersebut dibuat hanya pada bagaian sisi user umum/masyarakat yang akan mengakses sistem informasi layananan kesehatan. Pada penelitian ini akan dibangun integrasi data pada halaman administrator sistem informasi layananan kesehatan yang dapat mengintegrasikan data pada instansi kesehatan.
\end{abstract}

Kata Kunci : Pusat informasi, layanan, kesehatan

\section{LATAR BELAKANG}

Ketersediaan sistem informasi layanan kesehatan merupakan salah satu faktor yang tidak dapat dipisahkan dari sistem kesehatan di suatu negara. Dengan sistem tersebut, masyarakat akan dimudahkan untuk mendapatkan layanan kesehatan dari berbagai institusi kesehatan yang ada, disamping itu, masyarakat dapat berperan aktif dalam memberikan berbagai informasi tentang kesehatan yang terjadi di lingkungannya. 
Sebagian besar institusi di Kota Pekalongan, seperti rumah sakit, puskesmas, klinik kesehatan dan apotik, sudah menerapkan sistem informasi berbasis komputer, namun belum saling terintegrasi, sehingga tidak mudah bagi masyarakat untuk mendapatkan informasi terkait kesehatan, seperti informasi ketersediaan kamar rawat inap, informasi jadwal praktek dokter dan informasi ketersediaan darah. Selama ini, untuk mendapatkan informasi tersebut, masyarakat harus mengakses sistem informasi dari masing-masing institusi kesehatan, sehingga hal tersebut merepotkan jika memerlukan informasi waktu yang cepat dan akurat.

Berdasarkan uraian diatas maka ketersediaan satu sistem informasi layanan kesehatan yang mengintegrasikan semua institusi kesehatan di kota Pekalongan dan dapat diakses dengan mudah oleh masyarakat kota Pekalongan dari manapun dan kapanpun menjadi kebutuhan yang penting dan harus dapat diwujudkan.

\subsection{Rumusan Masalah}

Kota Pekalongan belum memilki sebuah sistem informasi layanan kesehatan yang mengintegrasikan semua institusi kesehatan di kota Pekalongan, serta yang mudah diakses oleh masyarakat dari manapun dan kapanpun. Belum adanya sistem informasi tersebut, tentunya menjadi kendala bagi masyarakat yang ingin secara cepat dan akurat mendapatkan informasi terintegrasi tentang layanan kesehatan yang tersedia di seluruh kota Pekalongan, masyarakat yang ingin menyampaikan keluhan kesehatan di lingkungannya dan yang ingin menyampaikan tingkat kepuasan dari layanan kesehatan yang diterima masyarakat, untuk dapat ditindaklanjuti institusi terkait.

Dari uraian di atas, sangat penting jika penelitian ini dapat mendukung penyelesaian kendala-kendala tersebut, sehingga untuk rumusan masalah dalam penelitian ini adalah: "Bagaimana Mengntegrasikan Informasi Kesehatan Pada Instansi Kesehatan Di Kota Pekalongan Melalui Sistem Informasi Layanan Kesehatan."

\subsection{Tujuan Penelitian}

Terbentuknya sistem informasi layanan kesehatan berbasis mobile yang mampu memberikan informasi yang akurat, tepat waktu dan mudah diakses dari manapun/kapanpun.

\subsection{Manfaat Penelitian}

Adapun manfaat sistem informasi layanan kesehatan berbasis mobile dalam suatu fasilitas kesehatan diantaranya: memudahkan masyarakat untuk mendapatkan informasi terkait layanan kesehatan, memudahkan dinas terkait untuk mendapatkan data tentang layanan kesehatan di kota Pekalongan, memudahkan peran aktif masyarakat dalam berpartisipasi di bidang kesehatan dan menjadi kontrol terhadap layanan kesehatan yang ada.

\section{LANDASAN TEORI}

\subsection{Penelitian Terkait}

Joseph Kasumba Sewanyana membuat ICT Access and poverty in Uganda (Sewanyana, 2007). Pada penelitian tersebut melalui akses ICT dapat membantu peningkatan komunikasi pribadi dan masyarakat terutama mendukung sektor pendidikan, kesehatan, pencarian kerja, dan pemerintah.

Penelitian Nela Safelia tentang Pengaruh Teknologi Sistem Informasi Baru terhadap Kinerja Individu (Safelia Nella, 2012). Hasil peneltian tersebut menyatakan 
bahwa adanya hubungan peningkatan kinerja individu dengan penerapan teknologi informasi.

Pada penelitian sebelumnya (Susanto, Christianto, \& Kurniawan, 2016) telah dibuat prototipe untuk sistem informasi layanan kesehatan. Akan tetapi prototipe tersebut dibuat hanya pada bagaian sisi user umum/masyarakat yang akan mengakses sistem informasi layananan kesehatan.

\subsection{Sistem Informasi Kesehatan}

Sistem Informasi Kesehatan adalah suatu sistem yang menyediakan dukungan informasi bagi proses pengambilan keputusan di setiap jenjang administrasi kesehatan, baik di tingkat unit pelaksana upaya kesehatan, di tingkat kabupaten/kota, di tingkat provinsi, maupun di tingkat pusat (Indonesia, 2011).

Sistem Informasi Kesehatan merupakan gabungan perangkat dan prosedur yang digunakan untuk mengelola siklus informasi (mulai dari pengumpulan data sampai pemberian umpan balik informasi) untuk mendukung pelaksanaan tindakan tepat dalam perencanaan, pelaksanaan dan pemantauan kinerja sistem kesehatan.

Informasi kesehatan selalu diperlukan dalam pembuatan program kesehatan mulai dari analisis situasi, penentuan prioritas, pembuatan alternatif solusi, pengembangan program, pelaksanaan dan pemantauan hingga proses evaluasi.

\subsection{Sistem Informasi Berbasis WEB}

Sistem informasi dahulu dibuat secara konvensional (aplikasi desktop). Namun seiring dengan perkembangan teknologi internet maka sistem informasi dibuat berbasis web karena sifatnya yang luas dan memungkinkan semua orang dapat mengakses informasi secara cepat dan mudah dari mana saja, sehingga pemasukan data dapat dilakukan dari mana saja dan dapat dikontrol dari satu tempat sebagai sentral.

World Wide Web(WWW) atau yang biasa disingkat dengan web ini merupakan salah satu bentuk layanan yang dapat diakses melalui internet. Web adalah fasilitas hypertext untuk menampilkan data berupa teks, gambar, bunyi, animasi, dan data multimedia lainnya, yang mana data tersebut saling berhubungan satu sama lainnya (Purbo, 2006).

\subsection{Peranan Sistem Informasi Kesehatan dalam Sistem Kesehatan}

Menurut Badan Kesehatan Dunia (World Health Organization, WHO), Sistem Informasi Kesehatan (SIK) merupakan salah satu dari 6 "building block" atau komponen utama dalam sistem kesehatan di suatu Negara. Keenam komponen ( building block ) sistem kesehatan tersebut adalah :

1. Pelaksanaan pelayanan kesehatan (Service delivery)

2. Produk medis, vaksin, dan teknologi kesehatan (Medical product, vaccine, and technologies)

3. Tenaga medis (Health worksforce)

4. Sistem pembiayaan kesehatan (Health system financing)

5. Sistem informasi kesehatan (Health information system)

6. Kepemimpinan dan pemerintah (Leadership and governance)

Sedangkan di dalam tatanan Sistem Kesehatan Nasional (SKN), Sistem Informasi Kesehatan (SIK) merupakan bagian dari sub sistem ke 6 yaitu pada sub sistem manajemen, informasi, dan regulasi kesehatan. Sub sistem manajemen dan informasi kesehatan merupakan subsistem yang mengelola fungsi-fungsi kebijakan kesehatan, administrasi kesehatan, informasi kesehatan, dan hukum kesehatan 
yang memadai dan mampu menunjang penyelenggaraan upaya kesehatan nasional agar berhasil guna, berdaya guna, dan mendukung penyelenggaraan ke- 6 subsistem lain di dalam SKN sebagai satu kesatuan yang terpadu.

Adapun sub sistem dalam Sistem Kesehatan Nasional Indonesia, yaitu:

1. Upaya kesehatan

2. Penelitian dan pengembangan kesehatan

3. Pembiayaan kesehatan

4. Sumber daya manusia (SDM) kesehatan

5. Sediaan farmasi, alat kesehatan,dan makanan

6. Manajemen, informasi, dan regulasi kesehatan

7. Pemberdayaan masyarakat.

Dalam pengembangan Sistem Informasi Kesehatan, harus dibangun komitmen setiap unit infrastruktur pelayanan kesehatan agar setiap sistem informasi kesehatan berjalan dengan baik dan yang lebih terpenting menggunakan teknologi komputer dalam mengimplementasikan Sistem Informasi Berbasis Komputer (Computer Based Information System) (Indonesia, 2011).

\section{PEMBAHASAN}

3.1 Alur Integrasi Yang diusulkan

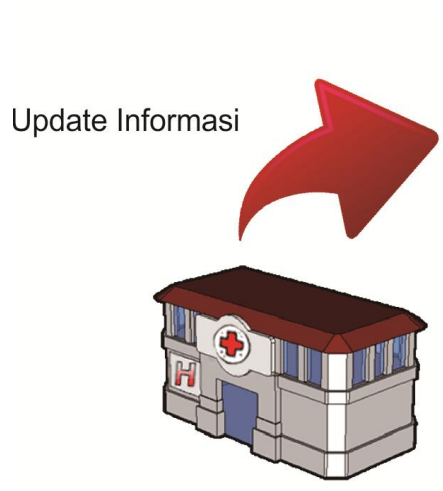

Instansi Kesehatan
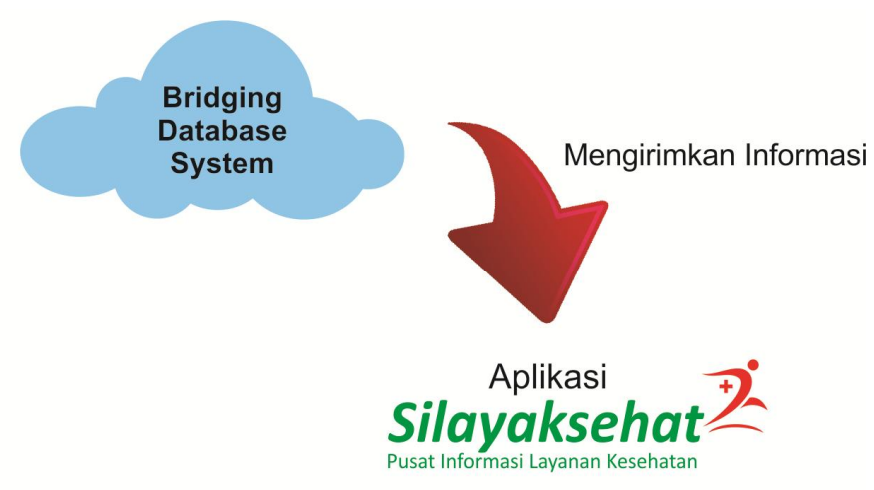

Gambar 3.1 Alur Integrasi Sistem

Instansi kesehatan yang telah menjadi member atau anggota pada sistem informasi layanan kesehatan (silayaksehat) dapat membagikan informasi yang akan di-publish melalui aplikasi brigding database. Selanjutnya aplikasi brigding database akan mengirimkan informasi tersebut ke sistem informasi layanan kesehatan. Informasi tersebut dapat berupa jadual dokter, informasi ruangan rawat inap, stok darah, dan informasi lainnya yang dibutuhkan.

\subsection{User dan Kewenangannya}

User atau pemakai pada aplikasi brigding database sistem informasi layanan kesehatan (silayaksehat) terdiri dari administrator dan member. Administrator dikelola oleh Pemerintah Kota Pekalongan, sedangkan member terdiri dari instansi kesehatan yang telah mendaftar menjadi anggota atau member. 
Tabel 3. 1 User dan Kewenangannya

\begin{tabular}{l|l|l}
\hline \multicolumn{1}{c|}{ User } & Tipe User & \multicolumn{1}{c}{ Kewenangan } \\
\hline Pemerintah Kota Pekalongan & & $\begin{array}{l}\text { mengelola menu } \\
\text { berita } \\
\text { mengelola menu } \\
\text { member }\end{array}$ \\
& Administrator & $\begin{array}{l}\text { mengelola menu } \\
\text { suara masyarakat }\end{array}$ \\
\hline - Puskesmas & & $\begin{array}{l}\text { Mengelola informasi } \\
\text { - Rumah Sakit }\end{array}$ \\
$\begin{array}{l}\text { - Apotik } \\
\text { - PMI }\end{array}$ & Member & $\begin{array}{l}\text { yang akan ditampilkan } \\
\text { - Instansi Kesehata Lainnya }\end{array}$ \\
\hline
\end{tabular}

\subsection{Desain Sistem}

3.3.1 Halaman Admin

a. Halaman Login

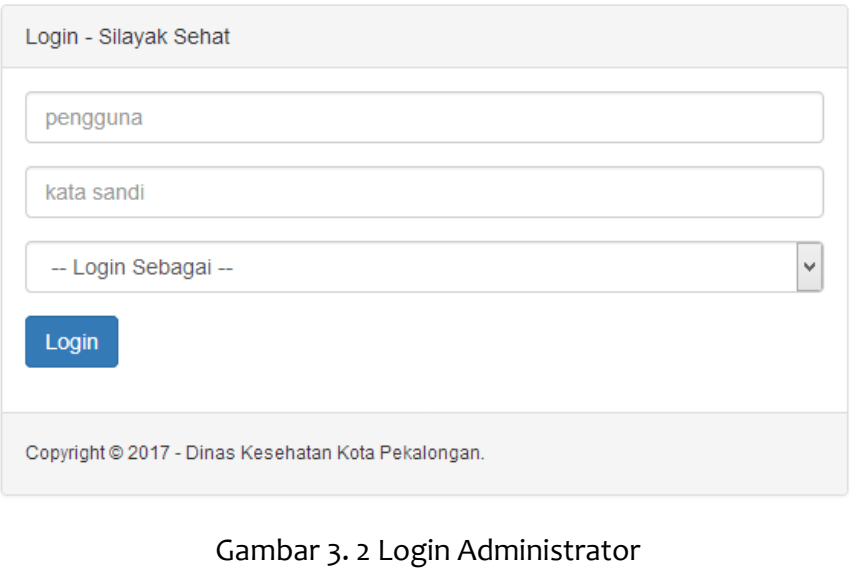

Halaman login digunakan oleh administrator untuk masuk ke dalam sistem. Admin diwajibkan untuk menginput username, password, dan memilih tipe user. Jika valiadasi penginputan tidak terdapat kesalahan maka admin dapat mesuk ke halaman beranda administrator.

b. Halaman Beranda

Halaman beranda administrator terdiri dari tiga menu utama, yaitu berita, member, laporan pelayanan, laporan masyarakat.

\section{BERITA LAPORAN PELAYANAN LAPORAN PENYAKIT MEMBER LOGOUT}

Gambar 3. 3 Halaman Beranda Administrator

\section{Menu Berita}

Menu Berita digunakan untuk mengelola berita yang akan di-publish. Melalui menu berita admin dapat menambah, mengedit dan menghapus berita. 
Berita Laporan pelayanan Laporan penyakit Member Logout

O Add Berita

\begin{tabular}{|c|c|c|c|c|c|c|c|}
\hline Show $10 \vee$ entric & & & & \multicolumn{4}{|c|}{ Search: } \\
\hline Tanggal & Judul & $\therefore$ & Isi & $\hat{\mathrm{v}}$ & & & Actions \\
\hline 12/09/2016 & Pekalongan Hebat & & Pemerintah kota pekalongan luncurkan. & & (a) View & $\therefore$ Edit & - Delete \\
\hline Search Tanggal & Search Judul & & Search Isi & 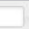 & & Clear & tering $\$$ \\
\hline
\end{tabular}

Gambar 3. 4 Menu Berita

\section{Menu Member}

Menu Member digunakan untuk mengelola member atau anggota. Melalui menu member admin dapat menambah, mengedit, dan menghapus member atau anggota.

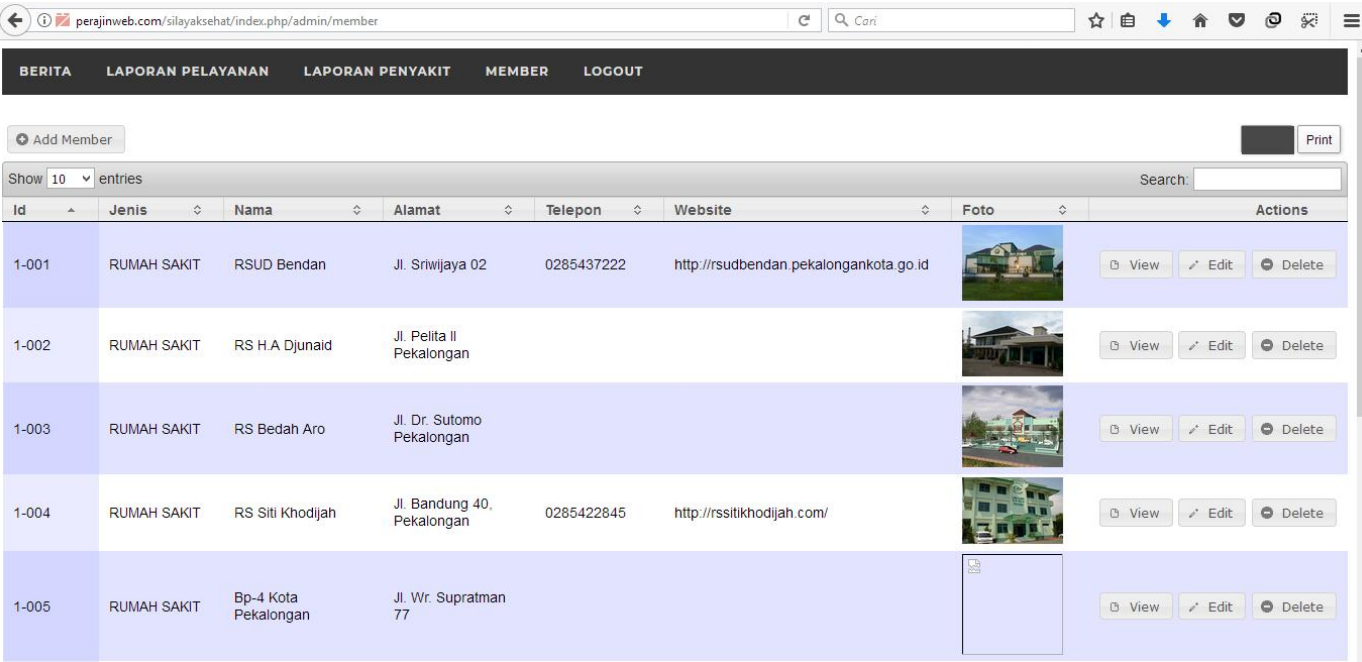

Gambar 3. 5 Menu Member

\section{Menu Laporan Pelayanan dan Laporan Penyakit}

Menu suara masyarakat diugnakan untuk mengelola keluhan, pesan, laporan dari masyakarat.

\section{Bertita Laporan pelayanan Laporan penYakit member Locout}

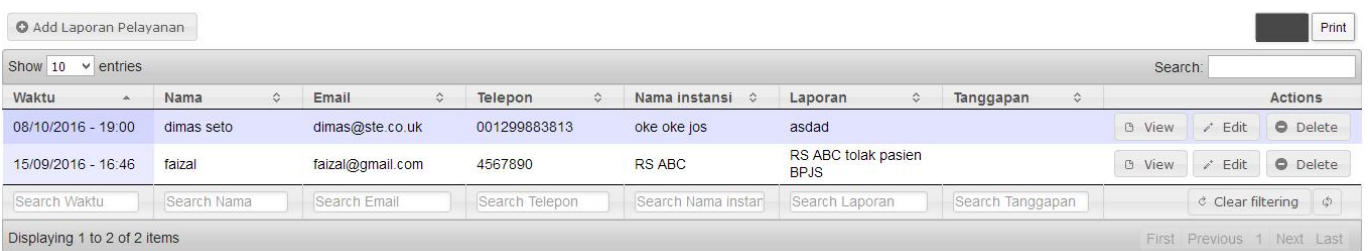

Gambar 3. 6 Menu Lapor Pelayanan

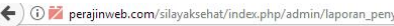

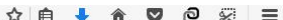
Berita LAPORAN PELAYANAN LAPORAN PENYAKIT MEMBER LOGout

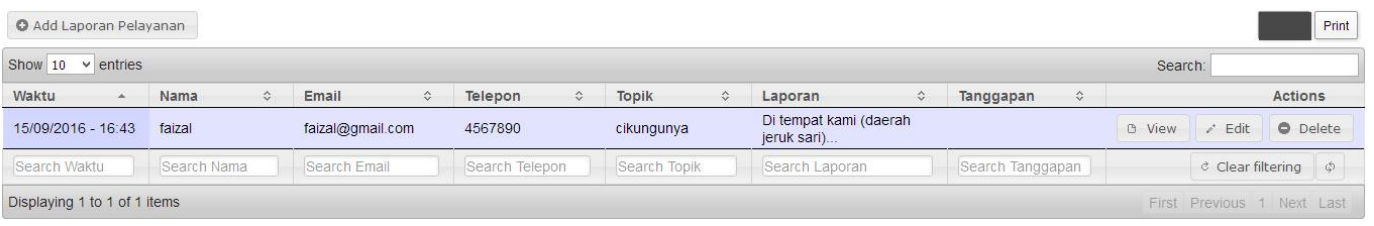

Gambar 3. 7 Lapor Penyakit 


\subsubsection{Halaman Member}

a. Halaman Login

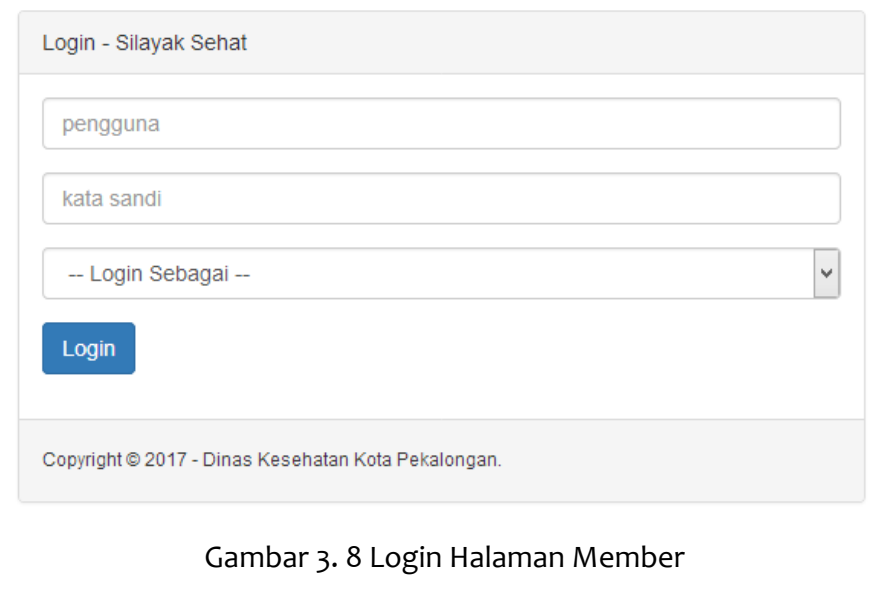

Halaman login digunakan oleh member untuk masuk ke dalam sistem. Admin diwajibkan untuk menginput username, password, dan memilih tipe user. Jika valiadasi penginputan tidak terdapat kesalahan maka admin dapat mesuk ke halaman beranda member.

b. Halaman Beranda

Halaman beranda member dapat disesuikan dengan kebutuhan informasi dari member yang akan dipublish ke masyarakat umum. Berikutn ini halaman beranda untuk member rumah sakit atau puskesmas.

\section{FASILITAS INFO RUANGAN JADWAL DOKTER SINKRON DATA LOGOUT}

Gambar 3. 9 Halaman Beranda Member

Halaman beranda terdiri dari beberapa menu untuk mengelola informasi yang akan dipublish sesuai dengan kebutuhan informasinya. Pada halaman ini juga terdapat menu sinkron data yang digunakan untuk mengirimkan data ke sistem informasi layanan kesehatan.

\section{Menu Fasilitas}

Menu fasilitas digunakan oleh member untuk menambah, mengedit, dan menghapus informasi fasilitas yang dimilikinya.

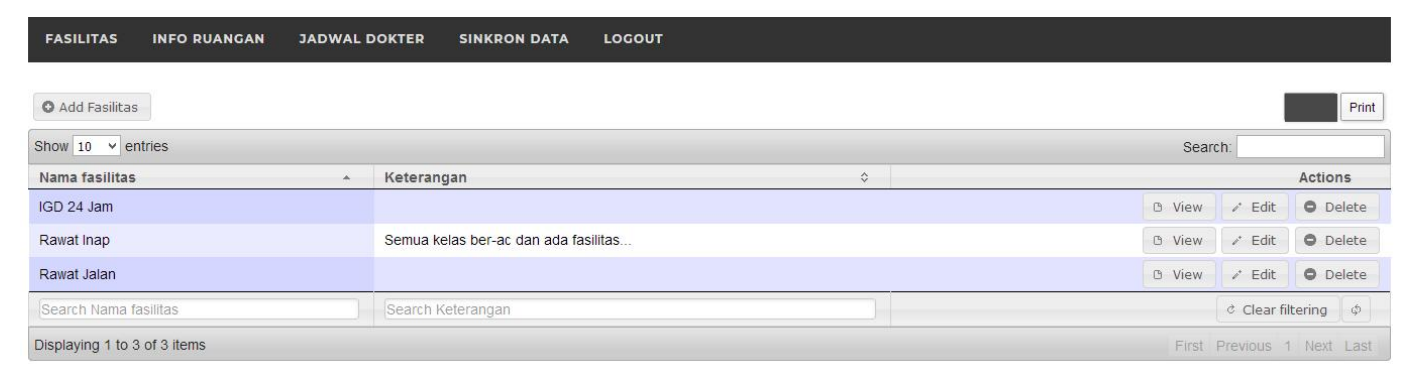

\section{Menu Info Ruangan}

Gambar 3. 10 Menu Fasilitas

Menu info ruangan digunakan oleh member untuk menambah, mengedit, dan menghapus informasi ruangan yang dimilikinya. 


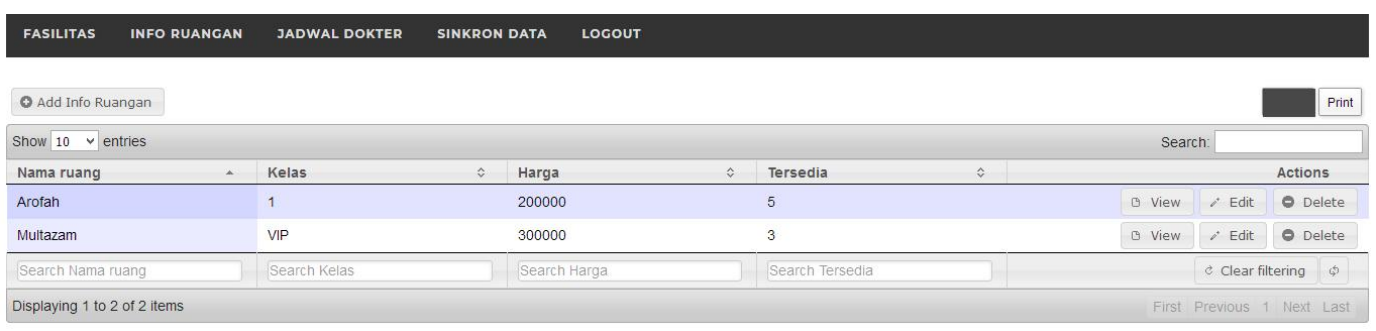

Gambar 3. 11 Menu Info Ruangan

\section{Menu Jadual Dokter}

Menu jadual dokter digunakan oleh member untuk menambah, mengedit, dan menghapus informasi jadual dokter yang dimilikinya.

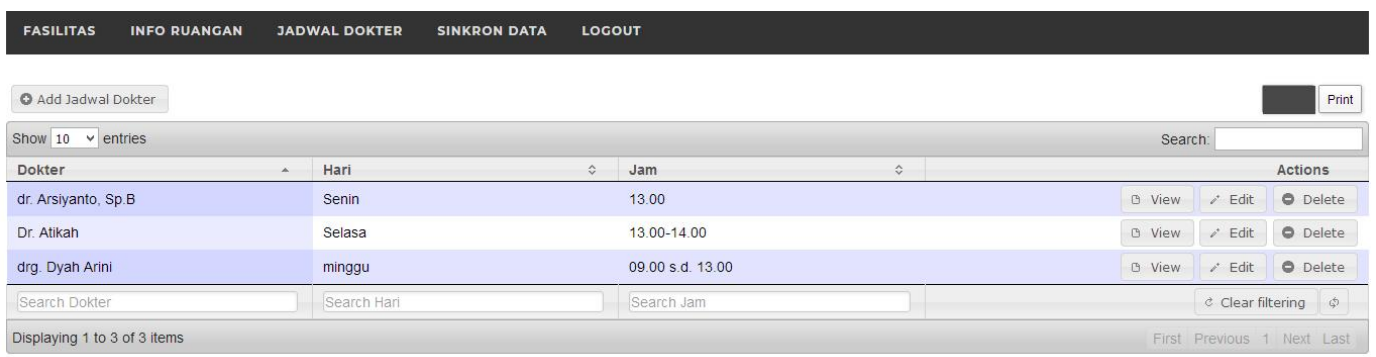

\section{Menu Sinkron Data}

Gambar 3.12 Menu Jadual Dokter

Menu sinkorn data digunakan sebagai jembatan database pada database member dengan sistem informasi layanan kesehatan. Sehingga setiap terdapat perubahan informasi atau data, member cukup mengklik menu sinkron data untuk mengupdate informasi ke sistem layanan kesehatan.

FASILITAS INFO RUANGAN JADWAL DOKTER SINKRON DATA LOGOUT

\section{PENUTUP}

Gambar 3. 13 Menu Sinkron Data

\subsection{Kesimpulan}

Sistem informasi layanan kesehatan yang diusulkan dapat menghubungkan data pada database yang dimiliki oleh member dengan database sistem informasi layanan kesehatan. Sehingga dengan demikian informasi dari member/instansi kesehatan dapat terintegrasi dengan sistem informasi layanan kesehatan.

\subsection{Saran}

Pada sistem informasi layanan kesehatan yang diusulkan membutuhkan akses database ke instansi kesehatan yang akan memberikan informasinya. Sehingga untuk mengakses informasi tersebut diperlukan izin dalam mengakses data. Untuk itu diperlukan regulasi atau peraturan daerah atau payung hukum yang memuat hal tersebut.

\section{DAFTAR PUSTAKA}

Indonesia, K. K. (2011). Pedoman Informasi Kesehatan. Jakarta: Kementrian Kesehatan Republik Indonesia.

Purbo, O. W. (2006). Buku Pegangan Internet Wireless dan Hotspot. Jakarta: PT. Elex Media Komputindo.

Safelia Nella, d. (2012). Pengaruh Teknologi Sistem Informasi Baru terhadap Kinerja Individu. Jurnal Penelitian Universitas Jambi. 
Sewanyana, J. K. (2007). ICT Access and poverty in Uganda. International Journal of Computing and ICT Research, Vol. 1, No. 2, 2.

Susanto, E. B., Christianto, P. A., \& Kurniawan, M. F. (2016). Sistem Informasi Layanan Kesehatan Berbasis Mobile Yang Mengintegrasikan Instansi Layanan Kesehatan di Kota Pekalongan. Volume 16 . 